D.O.I.: $10.3895 / \mathrm{S} 1808-04482011000200012$

\title{
RECICLAGEM DE FOLHAS DE ALUMÍNIO EM FORNO ELÉTRICO À INDUÇÃO
}

\section{RECYCLING OF ALUMINUM FOIL IN THE INDUCTION FURNACE}

\author{
Antão Rodrigo Valentim ${ }^{1}$; Ivanir Luiz de Oliveira $^{2}$ \\ ${ }^{1}$ Instituto Federal do Paraná - IFPR - Paranavaí - Brasil \\ valentim.ro@gmail.com \\ ${ }^{2}$ Universidade Tecnológica Federal do Paraná - UTFPR - Ponta Grossa - Brasil \\ ivanir@utfpr.edu.br
}

\begin{abstract}
Resumo
O objetivo do presente trabalho foi estudar a eficiência no processo de reciclagem de alumínio a partir da fusão de folhas finas de alumínio, com espessura de 0,03mm, em forno elétrico à indução, e na produção da liga SAE 329. As folhas de alumínio não sofreram nenhum tipo de tratamento nem passaram por processo de trituração. Elas foram agrupadas e acondicionadas no cadinho do forno manualmente. Foram realizadas 79 fusões, obtendo um rendimento médio de 92,9\%. Comparações com rendimentos obtidos, com outros tipos de sucatas em diferentes tipos de fornos, foram realizadas. Apesar da pequena espessura das folhas de alumínio, fato que influencia diretamente na diminuição do rendimento do processo, a recuperação em forno elétrico à indução mostrou-se eficiente.
\end{abstract}

Palavras-chave: reciclagem de alumínio; folhas de alumínio; forno à indução; fundição.

\section{Introdução}

A reciclagem do alumínio é vantajosa do ponto de vista socio-econômico e ambiental. O problema ocorre quando os custos e margens esperadas pelas empresas recicladoras são maiores que os preços de venda praticados pelas grandes empresas de alumínio primário. Isso faz com que as recicladoras deixem de ser competitivas.

O alumínio é uma commodity cujo valor monetário é estabelecido com base na oferta e demanda e fatores conjunturais. Seu preço é fixado pelas grandes empresas do setor que têm como referência a LME (Bolsa de Mercadoria de Londres). No Brasil, a LME é utilizada como referência desde 1990 (LOUREIRO FILHO, 2006).

A formação do preço de venda do alumínio e suas ligas, pelas grandes empresas do setor, é algo particular. As margens de lucro com que elas trabalham e os custos são levados em consideração. $\mathrm{Na}$ composição de preço do alumínio, e suas ligas, também são levados em consideração a logística de aquisição dos materiais e sua distribuição. Empresas que produzem ligas de alumínio secundário, ou seja, provenientes da reciclagem, têm como referência os preços 
praticados pelas empresas produtoras de alumínio primário.

Um fator importante a favor do crescimento da reciclagem do alumínio é o baixo consumo de energia no processamento da sucata. Para reciclar o alumínio gasta-se $0,7 \mathrm{kWh} / \mathrm{kg}$ de energia, enquanto que no processo primário tem-se um gasto de $14 \mathrm{kWh} / \mathrm{kg}$. (SZENTE et al., 1997). A economia de energia elétrica alcançada com a reciclagem é da ordem de 95\%, se comparada ao processo convencional, por eletrólise, utilizado na produção do alumínio primário.

No ano de 2008, o Brasil reciclou 36,6\% do alumínio consumido, correspondente a 412,3 mil toneladas de sucatas. Este índice é superior à média mundial de 31,3\%. Destaque para a reciclagem de latas de alumínio; em 2009 o Brasil liderou pelo $9^{\circ}$ ano consecutivo a líderança mundial de reciclagem com 98,2\%, o que correspondeu a 198,8 mil toneladas no ano. (ABAL, 2011a).

Há uma grande participação das latas no índice da reciclagem do alumínio no Brasil, isto poderia ser explicado pelo seu curto tempo de vida útil e sua reciclabilidade. De fato, a cadeia da reciclagem de latas está melhor estabelecida que outros materiais de alumínio.

De forma geral, a produção de alumínio secundário opera com custos elevados devido a fatores como: logística, disponibilidade, custos e qualidade das matérias-primas. Já os seus produtos, concorrem com os grandes grupos produtores de alumínio primário. Segundo Diniz (2007), isto explicaria em parte os níveis de reciclagem de aproximadamente 37\% no Brasil.

A vida útil de muitos produtos de alumínio é longa, o que diminui a sua presença nos descartes urbanos e industriais. No entanto, materiais como folhas de alumínio, também muito empregadas no setor de embalagens, são difíceis de serem recicladas. Folhas de alumínio possuem menores espessuras do que as latas e apresentam níveis de contaminação variados.

A forma como a coleta de sucata de alumínio está organizada e suas relações comerciais é algo complexo, muitos são os atores que compõem esta rede e o caminho percorrido pela sucata de alumínio pode tomar diferentes rumos até ser reciclada novamente.

A figura 1 mostra as diversas fases da reciclagem. Após a coleta do alumínio ocorre o seu processamento em centrais de reciclagem, que normalmente o comercializa para as indústrias fundidoras (POPOVICI, 1999).

$\mathrm{Na}$ cadeia da reciclagem, o papel das fundidoras é o de inserir o alumínio no mercado sob a forma de produtos acabados ou como matérias primas, sob a forma de ligas normalizadas.

Dentro da rede de reciclagem de alumínio, a fidelização entre os atores que compõem a cadeia da coleta é extremamente fraca, imperando, na maioria dos casos, o valor monetário pago pelo material. Segundo Vieira; Paula (2009), que estudaram o campo organizacional da reciclagem da lata de alumínio no estado do Rio de Janeiro, constataram que o maior interesse, ou seja, o que move a reciclagem da lata é o interesse econômico. 
Os mesmos identificaram que dentro das relações comerciais existe uma estrutura de dominação impostas pelos grandes sucateiros e as centrais de reciclagem, conforme a necessidade interna das mesmas. O valor da sucata, diferentemente do valor das ligas de alumínio, não está atrelado a padrões definidos, como por exemplo, a $L M E$. São determinados, conforme o interesse daqueles que estão no topo da cadeia da reciclagem.

Figura 1- Fluxo de operação industrial do alumínio secundário

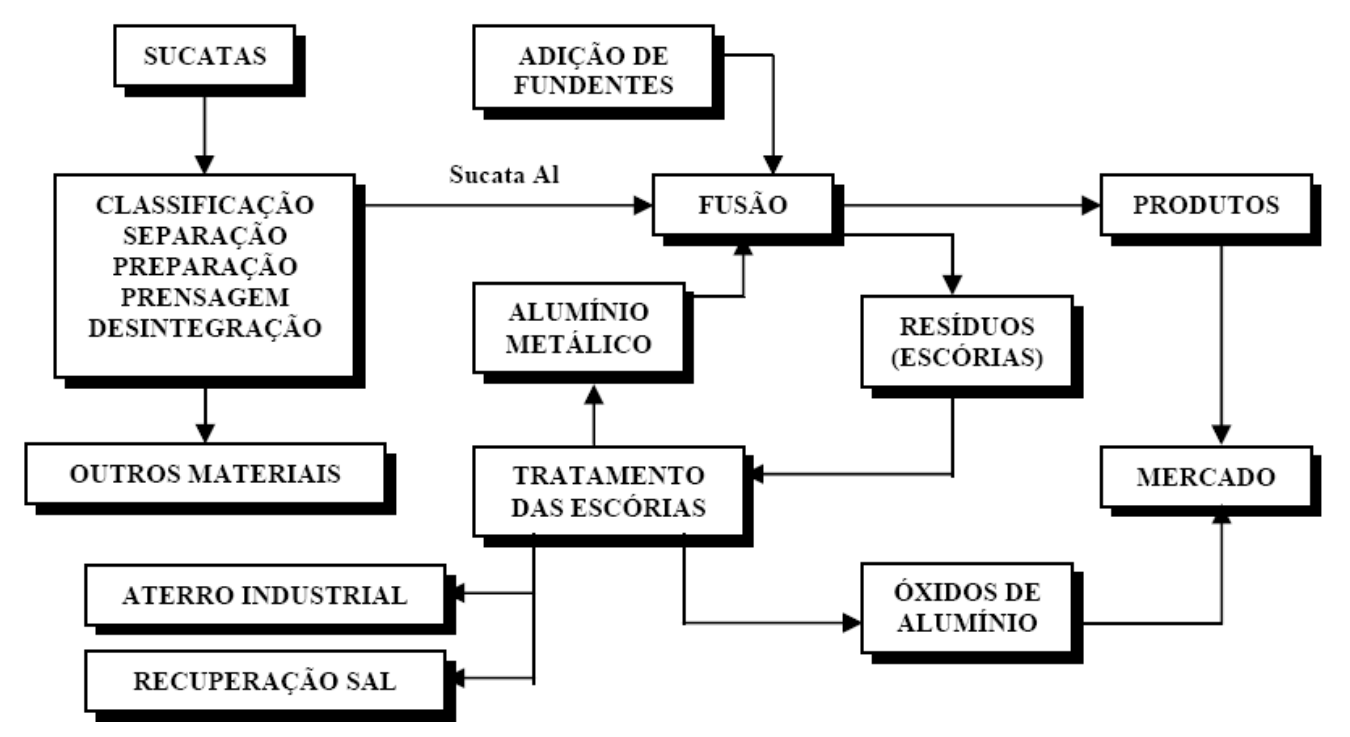

Fonte: Popovici (1999)

As grandes empresas de reciclagem de alumínio possuem laços comerciais mais estreitos com os grandes comerciantes de sucatas, pois esses possuem maior capital de giro, se comparado aos pequenos sucateiros, centrais de coletas e associações. Assim as vantagens conseguidas pelas empresas de reciclagem são maiores, como: preços mais baixos, devido à quantidade comprada, parcelamento da compra e maiores prazos para pagamentos.

Já as compras que ocorrem entre os grandes comerciantes de sucatas e os demais níveis da cadeia da coleta da sucata de alumínio são à vista ou há o adiantamento do pagamento para assegurar a compra do material que ainda será coletado. O pagamento adiantado é uma tentativa de fomentar e fidelizar os atores que estão em níveis mais baixo da cadeia da coleta da sucata do alumínio.

\section{Classificação das sucatas de alumínio}

As diferentes sucatas de alumínio são agrupadas em classes que retratam o processo de fabricação do produto que as geraram ou refletem a sua composição química. De fato, na fase da coleta e seleção os agentes ambientais procuram classificar o alumínio seguindo orientações do mercado. Um dos fatores é o grau de contaminação da sucata. São exemplos de contaminação: 
tinta, materiais plásticos e metálicos.

O mercado tem se ajustado para o melhor aproveitamento das sucatas de alumínio recolhidas. Uma classificação é a apresentada pela ABAL (2006, c). O Quadro 1 mostra 20 grupos de sucatas de alumínio levantados no mercado nacional, tendo como base as indicações recomendadas pelo Institute of Scrap Recycling Industries (ISRI), associação norte americana que congrega as empresas que atuam na reciclagem de vários tipos de materiais.

\begin{tabular}{|c|c|}
\hline SUCATA & DESCRIÇÃO \\
\hline Bloco & $\begin{array}{l}\text { Blocos de alumínio isentos de contaminantes (ferro e outros), com teor de } 2 \% \text { de óleos e/ou } \\
\text { lubrificantes. }\end{array}$ \\
\hline Borra & $\begin{array}{l}\text { Escória com teores variáveis de alumínio e percentual de recuperação a ser estabelecido entre } \\
\text { vendedor e comprador }\end{array}$ \\
\hline Cabo & Cabo com alma de aço. Retalhos de cabos de alumínio não ligados, usados, com alma de aço. \\
\hline Cavaco & $\begin{array}{l}\text { Cavacos de alumínio de qualquer tipo de liga, com teor máaximo de } 5 \% \text { de umidade/óleo, } \\
\text { isentos de contaminantes (ferros e outros). }\end{array}$ \\
\hline Perfil & Retalhos de perfis sem pintura. \\
\hline Chaparia & $\begin{array}{l}\text { Retalhos de chapas e folhas, pintadas ou não, com teor máximo de } 3 \% \text { de impurezas (graxas, } \\
\text { óleos, parafusos, rebites etc.); chapas usadas de ônibus e baús, pintadas ou não; tubos aerossol } \\
\text { (sem cabeças); antenas limpas de TV; cadeiras de praia limpas (isentas de plástico, rebites e } \\
\text { parafusos). }\end{array}$ \\
\hline Chaparia mista & Forros, chapas decorativas e persianas limpas (sem corrosões ou outras impurezas). \\
\hline Chapas off-set & $\begin{array}{l}\text { Chapas litográficas soltas, novas ou usadas, da série } 1000 \text { e/ou 3000, isentas de papel, plástico e } \\
\text { outras impurezas. }\end{array}$ \\
\hline Estamparia branca & $\begin{array}{l}\text { Retalhos de chapas e folhas, sem pintura e outros contaminantes (graxas, óleos, parafusos, } \\
\text { rebites etc.) gerados em atividades industriais. }\end{array}$ \\
\hline Latas prensadas & $\begin{array}{l}\text { Latas e alumínio usadas decoradas, prensadas com densidade entre } 400 \mathrm{~kg} / \mathrm{m} 3 \text {, com fardos } \\
\text { palatizados ou amarrados em lotes de } 1.500 \mathrm{~kg} \text {, em média, com espaço para movimentação por } \\
\text { empilhadeira, teor máximo de } 2,5 \% \text { de impurezas, contaminantes e umidade. }\end{array}$ \\
\hline $\begin{array}{l}\text { Latas soltas ou } \\
\text { enfardadas }\end{array}$ & $\begin{array}{l}\text { Latas de alumínio usadas decoradas, soltas ou enfardadas em prensa de baixa densidade (ate } \\
100 \mathrm{~kg} / \mathrm{m} 3 \text { ), com teor máximo de } 2,5 \% \text { de impurezas, contaminantes e umidade. }\end{array}$ \\
\hline Panelas & $\begin{array}{l}\text { Panelas e demais utensílios domésticos ("alumínio mole"), isentos de cabos - baquelita, } \\
\text { madeira etc. - e de ferro - parafusos, rebites etc. }\end{array}$ \\
\hline Perfil branco & $\begin{array}{l}\text { Retalhos de perfis sem pintura ou anodizados, soltos ou prensados, isentos de contaminantes } \\
\text { (ferro, graxa, óleo e rebites). }\end{array}$ \\
\hline Perfis mistos & $\begin{array}{l}\text { Retalhos de perfis pintados, soltos ou prensados, com teor máximo de } 2 \% \text { de contaminantes } \\
\text { (ferro, graxa, óleo e rebites). }\end{array}$ \\
\hline Pistões & $\begin{array}{l}\text { Pistões automotivos isentos de pinos, anéis e bielas de ferro, com teor máximo de } 2 \% \text { de óleos } \\
\text { e/ou lubrificantes }\end{array}$ \\
\hline $\begin{array}{l}\text { Radiador } \\
\text { alumínio- } \\
\text { alumínio }\end{array}$ & $\begin{array}{l}\text { Radiadores de veículos automotores desmontados isentos de cobre, "cabeceiras" e outros } \\
\text { contaminantes (ferro e plástico). }\end{array}$ \\
\hline $\begin{array}{l}\text { Radiador } \\
\text { alumínio-cobre }\end{array}$ & $\begin{array}{l}\text { Radiadores de veículos automotores desmontados isentos de "cabeceiras" e outros } \\
\text { contaminantes (ferro e plástico). }\end{array}$ \\
\hline $\begin{array}{l}\text { Retalho industrial } \\
\text { branco de chapa } \\
\text { para latas }\end{array}$ & $\begin{array}{l}\text { Retalho de produção industrial de latas e tampas para bebidas, soltos ou prensados, isentos de } \\
\text { pinturas ou impurezas. }\end{array}$ \\
\hline
\end{tabular}




\begin{tabular}{|c|l|}
\hline Telhas & $\begin{array}{l}\text { Retalhos de telhas de alumínio, pintados em um ou em ambos os lados, isentos de parafusos ou } \\
\text { rebites de ferro, revestimentos de espuma ou assemelhados. }\end{array}$ \\
\hline
\end{tabular}

Fonte: ABAL (2006)

Apesar da reciclagem do alumínio ocorrer nas plantas de reciclagem; as associações, cooperativas, catadores, comerciantes de sucata, indústrias e a sociedade, têm papel fundamental no ciclo da reciclagem desse metal. A sociedade e as indústrias são responsáveis, pela correta destinação da sucata de alumínio pós-consumo, para os diversos níveis da cadeia da coleta. Os demais, na realização da classificação e pré-tratamento da sucata.

\section{Fase térmica da reciclagem (fusão)}

A fundição é uma fase crítica da reciclagem do alumínio. Nela são produzidas as ligas padronizadas para o mercado consumidor. Esta operação exige controle rígido de processo uma vez que a matéria prima compõe grande parte dos custos.

O alumínio possui grande afinidade pelo oxigênio e naturalmente forma uma camada fina de óxido que o protege a temperaturas ambientes. Porém, durante o processo de fusão, acima de $700^{\circ} \mathrm{C}$, e à exposição a atmosfera oxidante do forno, resulta numa espessa camada de óxido de alumínio $\left(\mathrm{Al}_{2} \mathrm{O}_{3}\right)$. Esta oxidação representa perda efetiva de matéria prima, agravada pelo arraste de alumínio metálico consigo.

As perdas na fusão podem ir acima de $25 \%$ como ilustra a figura 2 . Dois fatores que afetam as perdas são a temperatura e a relação área/peso; ou seja, quanto menor a espessura da sucata maior as perdas metálicas, e de forma exponencial. (ABAL, 2007, d). Encontram-se nesse grupo as folhas de alumínio, motivo deste trabalho.

Figura 2 - Perda na fusão em função da espessura do material

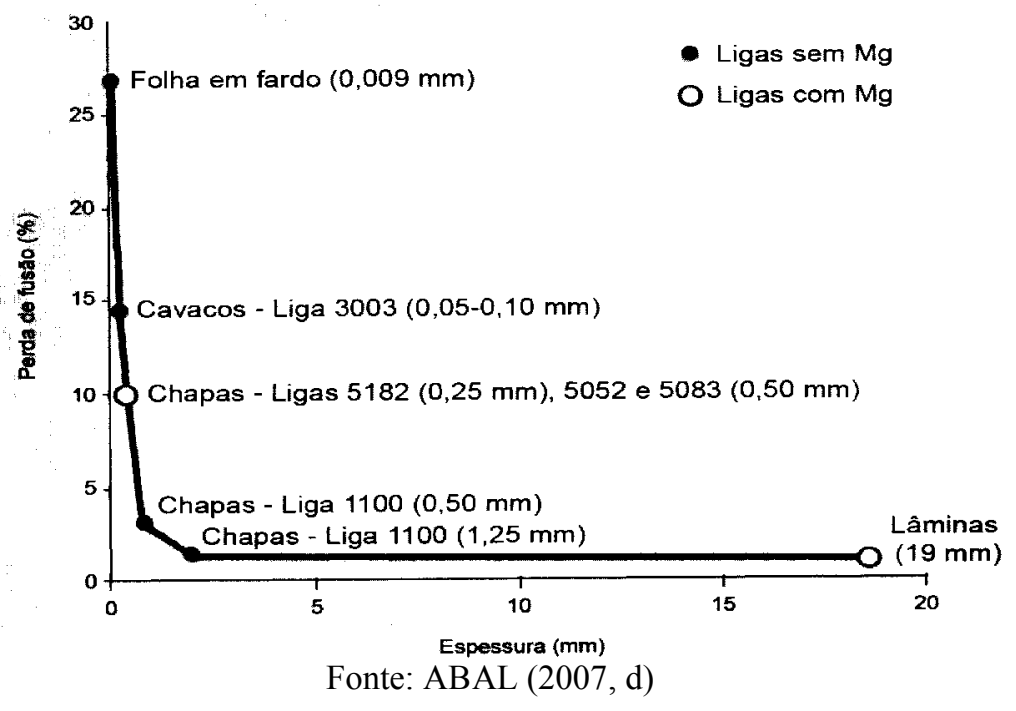

A camada de óxido formada denomina-se de "escórias de alumínio", resíduo cuja composição química depende da liga que está sendo produzida e da manipulação das matérias- 
primas necessárias ao processo.

Assim, apesar das vantagens de se reciclar o alumínio, o processo de fusão gera grandes quantidades de resíduos e perdas metálicas. Estima-se que no ano de 2005, o Brasil tenha produzido 170.000 toneladas de escórias de alumínio. (ABAL, 2007, d).

A escória do alumínio (dross) é um resíduo perigoso, que também pode ser chamada, de acordo com os teores de alumínio presente, em borra branca ou borra preta (salt cake). Basicamente as escórias são compostas por: alumínio metálico (65 a 75\%), óxido de alumínio (25 a 30\%), carbeto de alumínio (2 e 3\%), nitreto de alumínio (3 a 5\%), óxido de ferro (0,5 a 2\%) e óxido de silício (0,5 e 1,5\%). (ABAL, 2007, d).

Devido a elevada presença de alumínio metálico nas escórias, este tipo de resíduo é passível de comercialização por empresas licenciadas, desta forma, o valor oriundo dessa comercialização pode ser contabilizado pelas organizações como receita ambiental. No entanto, é um indicador negativo de rentabilidade e produtividade (DINIZ, 2007).

Entre os componentes das escórias estão sais de metais alcalinos (fluxos) intencionalmente adicionados durante o processo de fusão. Geralmente utiliza-se de 30\% a 40\% de fluxos, em peso, sobre a carga total do forno. Estas adições faz aumentar ainda mais a geração de resíduos. Porém, o objetivo dos fluxos é o de aumentar a produtividade, minimizando perdas metálicas.

Um fluxo muito utilizado é o salino, composto por cloreto de sódio $(\mathrm{NaCl})$ ou cloreto de potássio $(\mathrm{KCl})$, ou uma combinação entre eles. Duas composições utilizadas são: $60 \% \mathrm{NaCl}$ e $40 \%$ $\mathrm{KCl}$ (Szente, 1997); e a mistura equimolar desses dois sais $(50 \% \mathrm{NaCl}$ com $50 \% \mathrm{KCl})$. A última composição corresponde ao ponto eutético, ou seja, a menor temperatura de fusão dos mesmos, equivalente a $645^{\circ} \mathrm{C}$, figura 3. (ABAL, 2007d; TENÓRIO; ESPINOSA, 2002).

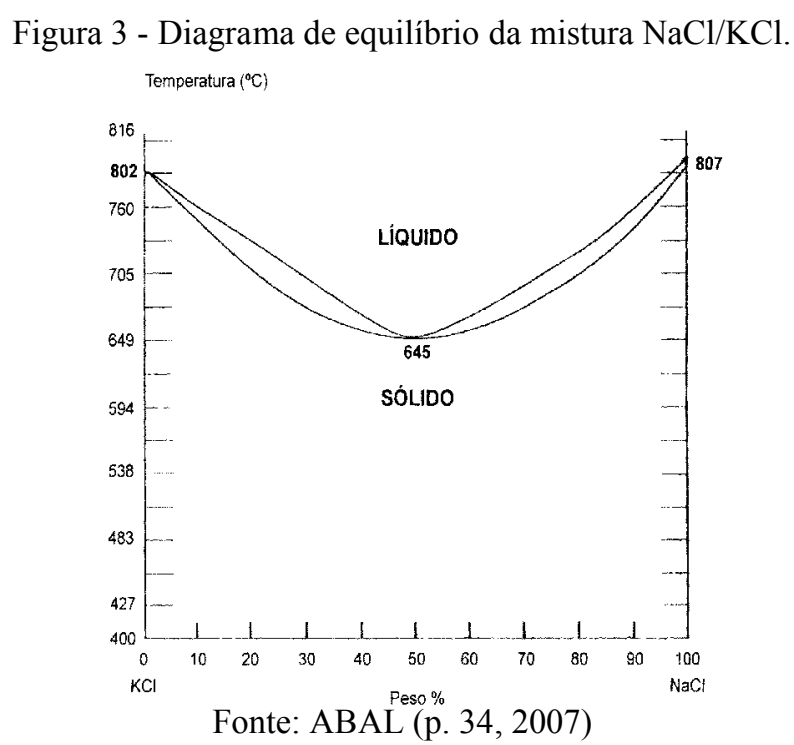

Tenório; Espinosa (2002), realizaram estudos para entender a influência da adição do fluxo salino no aumento da recuperação do alumínio. Constaram que o óxido forma uma camada que 
envolve o alumínio, o fluxo tem a função de romper essa camada e facilitar a coalescência das gotas de alumínio.

Uma melhora na viscosidade e no aumento da corrosão da camada de óxido de alumínio, foi verificada para uma adição de $\mathrm{NaF}$ e $\mathrm{KF}$ a mistura equimolar $\mathrm{NaCl}$ e KCl, (TENÓRIO et al., 2001). Nesta mesma linha, para conseguir uma melhor eficiência da camada de proteção do banho fundido, adições de $5 \%$ em peso de criolita $\left(\mathrm{Na}_{3} \mathrm{AlF}_{6}\right)$ diminui, ainda mais, a tensão superficial do óxido de alumínio, aderido na superfície da sucata, aumentando o rendimento metálico (XIAO; REUTER, 2002; ABAL, 2007).

Schmitz (2006, p. 85), apresenta uma classificação dos efeitos de diversos fluoretos e cloretos que podem ser utilizados nos fluxos salinos, de modo a melhorar a ação de coalescência do mesmo, quadro 2.

Quadro 2 - Composição de cloretos e fluorestos que podem compor os fluxos

\begin{tabular}{|l|l|}
\hline Excelente & $\mathrm{Na}_{3} \mathrm{AlF}_{6}<\mathrm{LiF}_{2} \mathrm{NaF}<\mathrm{NaF}<\mathrm{KF}$ \\
\hline Bom & $\mathrm{CaF}_{2}<\mathrm{MgF}_{2}$ \\
\hline Moderado & $\mathrm{AlF}_{3}, \mathrm{Mg} \mathrm{F}$ \\
\hline Pobre & $\mathrm{LiCl}<\mathrm{CaCl}_{2}<\mathrm{MgCl}_{2}$ \\
\hline
\end{tabular}

Fonte: Adaptado de Schmitz (2006, p. 85)

\section{Avanços nas técnicas de fusão}

Os fornos mais utilizados na reciclagem do alumínio são do tipo rotativos. Normalmente usam combustíveis fósseis e fluxo salino para prevenir excessivas perdas por oxidação do alumínio e facilitar o coalescimento e precipitação do metal líquido (BENDER; CRUZ, 2005). Estes equipamentos chegam a trabalhar com $30 \%$ a $40 \%$ de fluxo salino em relação a carga metálica em seu interior. $\mathrm{Na}$ operação, o fluxo é fundido e só depois ocorre o carregamento do forno com sucatas de alumínio. Por serem rotativos, com rotação de 2,5 a $5 \mathrm{rpm}$ para fornos horizontais (ABAL, 2007), estes equipamentos têm a vantagem de homogeneizar o banho metálico e transferir a este o calor sensível das paredes diretamente por condução o que melhora o rendimento térmico.

Os fornos horizontais alcançam rendimentos metálicos baixos, que variam de 50\% a 75\%. Porém, segundo Kurzawa (2006) a empresa Noviles, fabricante de laminados de alumínio, consegue rendimentos na fusão de latas de alumínio na ordem de $81 \%$, em fornos rotativos horizontais.

Devido as preocupações econômicas e ambientais para alcançar melhores índices de produtividade e consequentemente menores níveis de geração de resíduos, novas tecnologias foram implementas ao forno rotativo, de maneira a melhorar seu desempenho.

Khoei et al. (2003) analisou o comportamento térmico do forno rotativo, por meio da criação de um modelo em 2D e 3D, gerado pelo software ELFEN, da Rockfield Software Limited, para avaliar diversas posições da chama no interior do forno e diferentes velocidades de rotação. 
Sendo possível melhorar a produtividade do forno pela alteração e simulação destes dois parâmetros.

Fornos com melhores rendimentos, utilizam oxigênio como comburente e combústiveis fósseis mais leves (GLP ou GNV). Entre os vários fornos desenvolvidos, cita-se o forno rotativo basculante "Tiliting Rotary Furnace" (TRF). Este forno possui apenas um ponto de entrada e saída, opera em pressão positiva, o que reduz a utilização de fluxos de proteção do banho. Sua inclinação juntamente com seu sistema de rotação permite uma maior eficiencia térmica, reduzindo os ciclos de produção (NOKITA METAL, 2008).

Estudos mais recentes realizados pela Linde, empresa que atua no setor de produção de gases indutriais, introduz um novo conceito de forno rotativo, "Universal Rotary Titable Furnace" (URTF), que possui como diferencial a utilização de mais de uma entrada de oxígênio para auxilo na combustão, faz uso também de um refinado sistema de controle de queima, combinando um queimador oxi-combustível com recursos para controle de chama e para queima de eventuais componentes orgânicos e voláteis contidos na carga (óleos, vernizes e tintas). Neste processo admite-se o uso de sais fundentes, ainda que em quantidade reduzida (BENDER; CRUZ, 2005).

Destaca-se no Brasil, o desenvolvimento do forno com tocha a plasma, desenvolvido pelo IPT, com menor impacto ambiental e grande aporte térmico, foi projetado para reciclar o alumínio agregado aos materiais multicamadas, tipo longa vida, mas também permite recuperar alumínio de outros materiais, como é o caso das escórias de alumínio (BENDER; CRUZ, 2005).

\section{Fornos elétricos à indução}

Um forno pouco estudado para a reciclagem do alumínio, é o forno elétrico à indução, que possui como diferencial, se comparado a outros equipamentos utilizados na reciclagem, a capacidade de uma melhor homogeneização das ligas produzidas, devido a agitação gerada no banho fundido pelo campo eletromagnético, proveniente da indução (LUZGIN et al., 2004).

O forno elétrico à indução pertence à família dos fornos tipo cadinho (crucible furnace). Estes equipamentos são amplamente difundidos no setor metalúrgico de fundição.

Existem dois tipos de fornos elétricos à indução que podem ser aplicados à reciclagem do alumínio: forno elétrico à indução a canal (channel induction furnace) e forno elétrico à indução a cadinho, conhecido também como forno elétrico à indução sem núcleo (coreless induction furnace) (SCHMITZ, 2006). Como a presente pesquisa utilizou um forno elétrico à indução sem núcleo, será tratado somente o mesmo, com a denominação de forno elétrico à indução.

Para Schimitz (2006) o forno à indução é interessante para produção de ligas com alta qualidade. Verran et al. (2005) constatou que é superior a qualidade do alumínio secundário obtido em um forno elétrico à indução, pela baixa perda de elementos de ligas. 
Outro ponto a se destacar no forno à indução é a forma de aquecimento da carga. Induz-se corrente elétrica diretamente sobre a carga condutora levando-a à fusão, para isto, não há geração de emissões gasosas, algo importante para garantir a qualidade da liga, reduzir a oxidação da mesma, diminuir os impactos ambientais e melhorar as condições de trabalho para os trabalhadores da planta de reciclagem (SCHMITZ, 2006, p. 108).

$\mathrm{O}$ rendimento do processo de fusão da sucatas de alumínio está ligado diretamente à espessura do material (área específica), composição química, teores de contaminantes e forma de operação do forno. Smith (1994) realizou fusões com diversos tipos de materiais em um forno elétrico à indução e constatou índices de recuperação que variaram entre $85 \%$ a $96,5 \%$, dependendo do tipo de sucata a ser fundida.

A desvantagem desses equipamentos é a sua capacidade de carga. Os fornos elétricos à indução são utilizados em plantas de reciclagem onde não são necessárias grandes capacidades de fusão, se comparado aos fornos rotativos e revérberos, que podem atingir capacidades maiores que $20 t$ e 100t de alumínio fundido respectivamente (SCHMITZ, 2006). Porém, apesar da baixas capacidades, em média 10 toneladas, eles apresentam taxas de fusão consideráveis. Luzgin et al. (2004) apresenta informações sobre diversos modelos de fornos à indução utilizados na recuperação de sucatas de alumínio onde a taxa de fusão alcançada chega a 12,4 t/h. A Otto Junker fabrica fornos à indução com taxa de fusão 8,8 t/h de alumínio. (OTTO JUNKER, 2011).

Outro ponto importante é a quantidade de fluxo utilizados na produção nesses equipamentos. Vera; Kurzan (2008), utilizando forno à indução, estudaram a influência da variação da quantidade de fluxo, comercial a base de cloretos de sódio e potássio; e da temperatura de fusão, no rendimento do processo e na qualidade metalúrgica do lingote produzido. O estudo foi sobre latas de alumínio. A melhor produtividade alcançada foi de $90,8 \%$, obtida na fusão a temperatura de $850^{\circ} \mathrm{C}$ e utilizando $20 \%$ de fluxo.

O desenvolvimento de técnicas para recuperar alumínio de resíduos de baixo valor econômico é um desafio tanto técnico quanto ambiental. Samuel (2003) e Fogagnolo et al. (2003) estudaram formas alternativas para reciclar a sucata de alumínio em forma de cavaco. Consistiu na compactação do alumínio em alta pressão a frio ou a quente, sem que o material se fundisse. Mashhadi et al. (2008) constataram um aumento da produtividade na reciclagem de cavacos de alumínio, liga AA336, quando ocorria a compactação a frio dos mesmos juntamente com fluxo de proteção ( $\mathrm{KCl}, \mathrm{NaCl}$ e $\mathrm{KF})$. A medida em que a pressão de compactação aumentava, o rendimento aumentou. O melhor rendimento foi alcançado utilizando pé de banho para início da fusão, com uma pressão de compactação de $900 \mathrm{MPa}$.

Como visto anteriormente, folhas finas de alumínio possuem baixa produtividade. No entanto, trabalhos sobre estes materiais ainda são incipientes na literatura. Assim, o presente estudo 
teve por objetivo avaliar práticas que resultassem em aumento de produtividade para a reciclagem de folhas de alumínio com pequenas espessuras, da ordem de 0,03mm. Escolhendo fornos à indução, a pesquisa também objetivou aprofundar uso desta tecnologia na reciclagem do alumínio com vista à pequena escala. No sentido de valorizar o produto obtido, escolheu a fabricação de uma comercial, liga SAE 305. Finalmente, utilizou peso de lotes que refletissem melhor uma pequena escala de produção.

\section{Materiais e métodos}

A presente pesquisa estudou folhas de alumínio secundário (reciclado) avaliando técnicas de preparação e de fusão para o aumento da produtividade de lingotes a partir desses materiais.

Os trabalhos foram realizados no laboratório de fundição/CETEM do campus Ponta Grossa da UTFPR e contou com a parceria de uma empresa de base tecnológica e apoio financeiro da Fundação Araucária do Paraná.

Todos os processos de fusão ocorreram num forno elétrico à indução de potência máxima de $100 \mathrm{~kW}$ e freqüência fixa de 3000hz. Para análises químicas utilizou-se de um espectrômetro de Emissão Ótica Modelo Metal Lab.

Foram realizadas 79 corridas em cadinho de grafite com capacidade máxima de aproximadamente $55 \mathrm{~kg}$ de alumínio fundido/corrida. A liga preparada foi a SAE 305 a partir de folhas finas de alumínio. Correções químicas foram realizadas com silício metálico comercial.

A tabela 1 apresenta a composição química das folhas de alumínio e a tabela 2 as faixas de composição química da liga SAE 305, segunda à norma ABNT-NBR 13180.

Tabela 1 - Composição química da folha de alumínio $0,03 \mathrm{~mm}$

\begin{tabular}{ccccccccccc}
\hline Elementos & $\mathrm{Si}$ & $\mathrm{Fe}$ & $\mathrm{Cu}$ & $\mathrm{Mn}$ & $\mathrm{Mg}$ & $\mathrm{Cr}$ & $\mathrm{Ni}$ & $\mathrm{Zn}$ & $\mathrm{Ti}$ & $\mathrm{Al}$ \\
\hline Teor & $0,35 \%$ & $0,697 \%$ & $0,016 \%$ & $0,568 \%$ & $0,035 \%$ & $0,010 \%$ & $0,003 \%$ & $0,030 \%$ & $0,017 \%$ & $98,259 \%$ \\
\hline
\end{tabular}

Tabela 2 - Faixa de composição química liga SAE 305

\begin{tabular}{ccccccccccccc}
\hline Elementos & $\mathrm{Si}$ & $\mathrm{Fe}$ & $\mathrm{Cu}$ & $\mathrm{Mn}$ & $\mathrm{Mg}$ & $\mathrm{Cr}$ & $\mathrm{Ni}$ & $\mathrm{Zn}$ & $\mathrm{Ti}$ & $\mathrm{Sn}$ & $\mathrm{Outro}$ & $\mathrm{Al}$ \\
\hline Mínimo & $11,00 \%$ & - & - & - & - & - & - & - & - & - & - & - \\
Máximo & $13,00 \%$ & $1,00 \%$ & $0,60 \%$ & $0,35 \%$ & $0,10 \%$ & - & $0,50 \%$ & $0,35 \%$ & $0,00 \%$ & $0,15 \%$ & $0,25 \%$ & $83,70 \%$ \\
\hline
\end{tabular}

Fonte: ABNT-NBR 13180

Para o cálculo da carga de cada fusão, com o objetivo de obter a liga SAE 305, utilizou-se uma planilha eletrônica. A tabela 3 ilustra a quantidade de material utilizado em seis corridas, das 79 corridas realizadas, bem como a rendimento obtido nestas.

Tabela 3 - Tabela de carga de material de algumas corridas

\begin{tabular}{lcccccc}
\hline \multicolumn{1}{c}{ Material } & $\mathbf{0 1}$ & $\mathbf{0 2}$ & $\mathbf{0 3}$ & $\mathbf{0 4}$ & $\mathbf{0 5}$ & $\mathbf{0 6}$ \\
\hline Folha laminada $(\mathrm{kg})$ & 46,08 & 45,68 & 45,80 & 45,36 & 45,26 & 45,06 \\
Silício $(\mathrm{kg})$ & 6,40 & 6,40 & 6,40 & 6,40 & 6,40 & 6,40 \\
Carga Total $(\mathrm{kg})$ & 52,48 & 52,08 & 52,20 & 51,76 & 51,66 & 51,46 \\
\hline
\end{tabular}




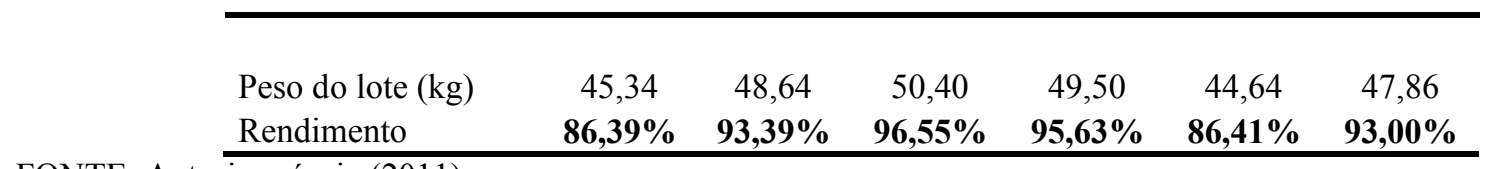

FONTE: Autoria própria (2011)

As folhas de alumínio, em forma de retalhos, foram unidas e dobradas de modo a obter fardos, para facilitar o carregamento do material e seu acondicionamento no interior do cadinho do forno, figura 4. O silício metálico utilizado na fabricação da liga tinha pureza de 99,48\% e granulometria entre 1 a $10 \mathrm{~mm}$.

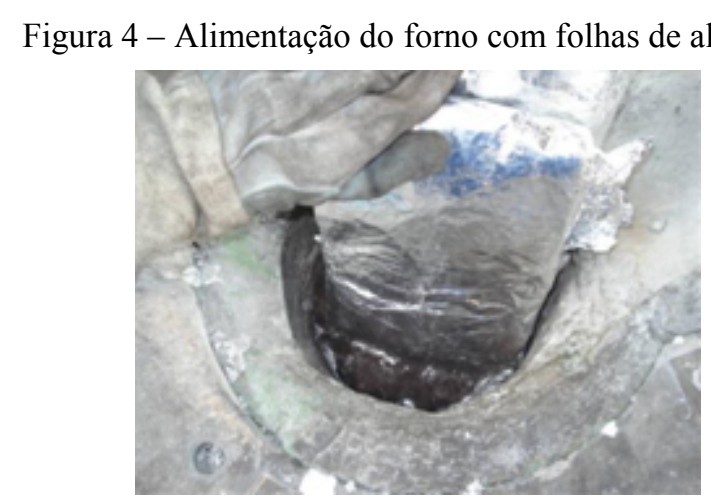

FONTE: Autoria própria (2010)

A alimentação do forno foi manual. O silício metálico era adicionado ao banho quando o alumínio fundido chegava a metade da capacidade do cadinho. A temperatura de trabalho variou entre $750^{\circ} \mathrm{C}$ a $780^{\circ} \mathrm{C}$.

Após a fusão do material iniciava-se a escorificação do alumínio fundido. A escorificação foi realizada com fluxo comercial, que foi adicionado em teores de $0,5 \%$ em peso, em relação a carga total, seguido por uma agitação do banho por 3 minutos, com auxílio de uma escumadeira devidamente preparada. Ao fim do processo retirava-se a escória gerada.

Em cada fusão foi retirada uma amostra, figura 5, que passava por um processo de usinagem para realização da análise química por espectrometria de emissão ótica.

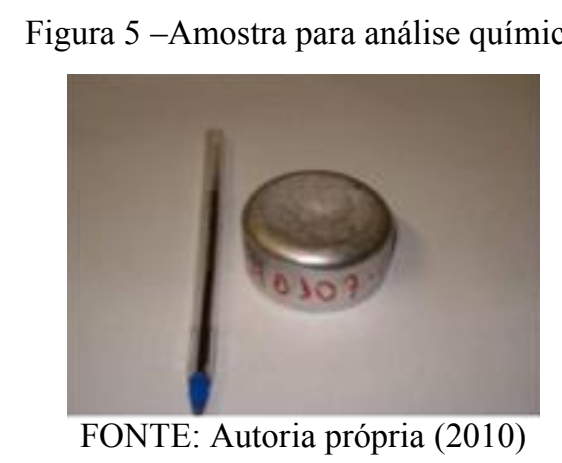

Estando o material dentro do campo da composição química da liga, especificada pela norma, ocorria o vazamento do alumínio em lingoteiras fabricadas em ferro fundido. Os lingotes produzidos tinham peso aproximados de $8 \mathrm{~kg}$. O tempo das corridas foram entre 60 a 70 minutos, 
considerado desde a alimentação até o vazamento da liga nas lingoterias.

\section{Resultados e discussão}

A produtividade média obtida no presente estudo foi de $92,9 \%$. O maior valor foi de $96,5 \%$ e o menor de $88,6 \%$. A figura 6 apresenta os rendimentos obtidos em cada fusão. Segundo Kurzan (2006) a empresa Noviles consegue rendimentos na fusão de latas de alumínio na ordem de $81 \%$, em fornos rototivos convencionais, devido ao pré-beneficiamento realizado da sucata. Fornos basculantes do tipo $T R F \AA$, apresentam apresentam rendimento da ordem de $85 \%$ (NOKITA METAL, 2008).

Figura 6 - Rendimentos obtidos nas fusões

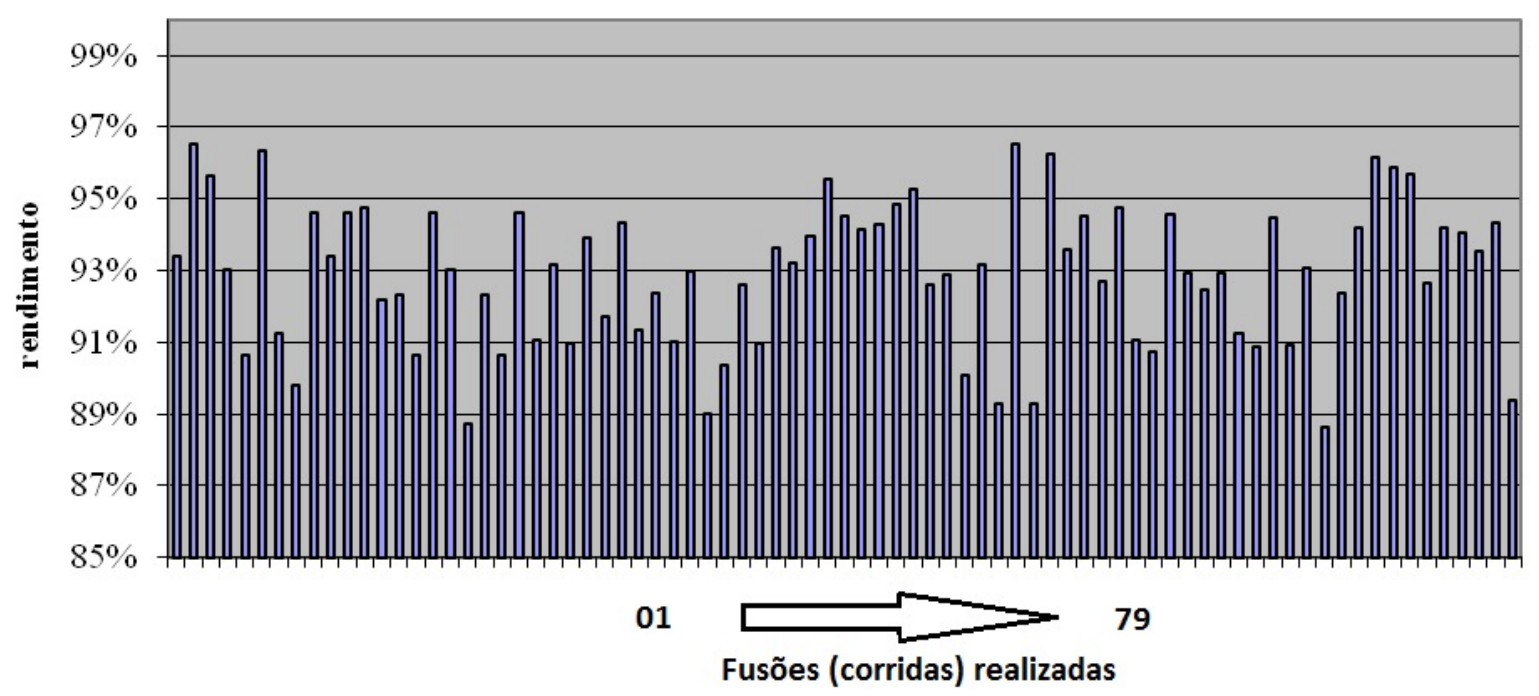

FONTE: Autoria própria (2010)

Estudo realizado por Bender; Cruz (2005) sobre fusões de diversos materiais, como lata, bloco, cavaco seco e prensado e lingote, utilizando o forno a plasma, apresentou respectivamente rendimentos de 78,6\%; 91,9\%; 96,1\% e 97,5\%.

A figura 7 apresenta um comparativo entre o presente resultado e os rendimentos obtidos em outros trabalhos, com diferentes tipos de sucatas de alumínio e em diferentes fornos de fusão. 
Figura 7 - Comparação entre o resultado do presente trabalho, em forno à indução (folha), com o obtido em outras pesquisas e com fornos e sucatas diferentes

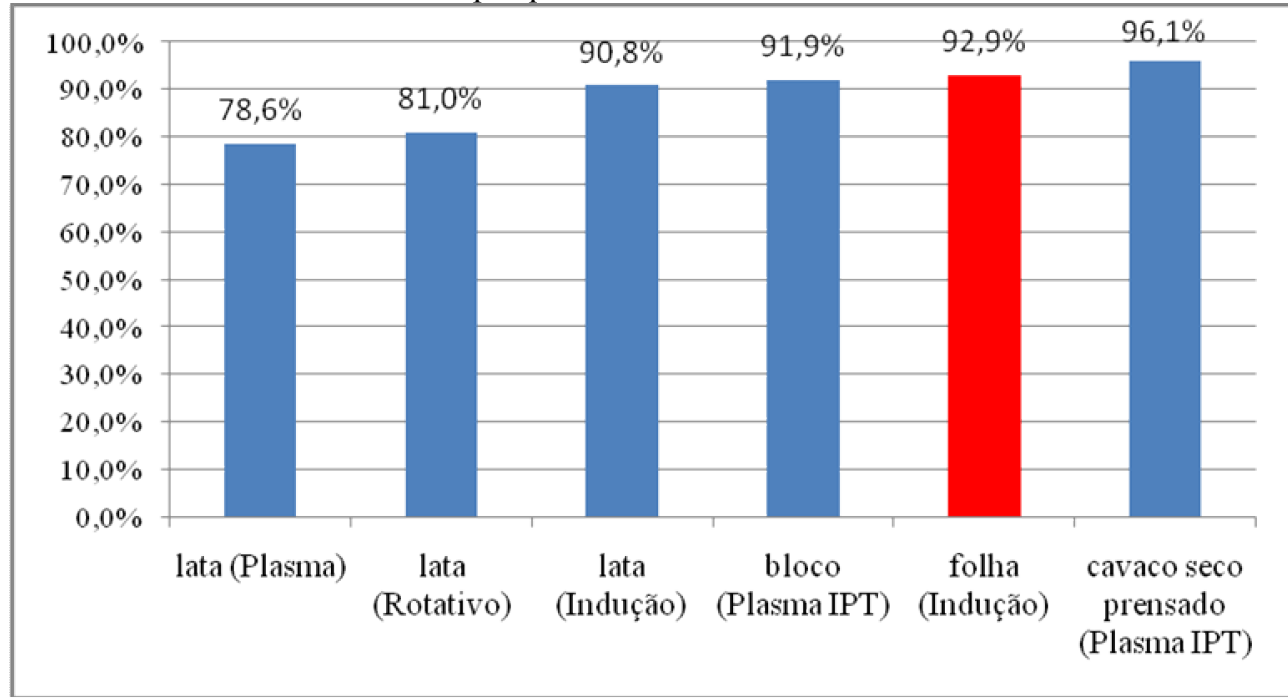

FONTE: Autoria própria (2010)

Percebe-se na figura 4 que o resultado obtido pela fusão de laminado em forno elétrico à indução, foi semelhante às sucatas mais densas, tradicionais na cadeia da reciclagem. $O$ rendimento ficou menor do que os cavacos secos. Segundo o autor deste trabalho, os cavacos estavam previamente compactados e livres de contaminantes, como óleos lubrificantes provenientes da usinagem (SAMUEL, 2002; FOGAGNOLO et al., 2003).

Kurzawa (2006) estudou o forno à indução na fusão de latas de alumínio, considerados materiais de pequena espessura, alcançando um rendimento igual a 90,8\%, maior do que outros equipamentos.

Assim, o presente trabalho confirma a eficácia do forno elétrico à indução como alternativa para materiais com pequenas espessuras e aumenta a oportunidade para o uso de folhas finas de alumínio na cadeia da reciclagem. Sua flexibilidade, aporte térmico e a possibilidade de fabricação de outros materiais metálicos, diferencia o forno à indução na busca para a maior sustentabilidade econômica para os pequenos fundidores na cadeia da reciclagem do alumínio.

\section{Comentários Finais}

Foram coletados rendimentos de 79 fusões (corridas) realizadas na fabricação da liga comercial SAE 305, utilizando resíduos de folhas finas de alumínio com 0,03mm de espessura, obtendo um rendimento médio de 92,9\%. Este valor foi equivalente às sucatas tradicionais. Apesar do forno à indução ser pouco empregado na reciclagem do alumínio, os resultados apontam para um grande potencial para o seu uso no desenvolvimento de novas técnicas de reciclagem.

\section{Abstract}

The present study investigates the efficiency in aluminum foil recycling process where each foil has 
a thickness of $0,03 \mathrm{~mm}$, using induction furnace, in the production of alloy SAE 329. The aluminum foil did not suffer any treatment or grinding, and they were grouped and packed in the crucible of the furnace manually. In the total, 79 processes were developed, obtaining a recovery yield of $93 \%$. Comparisons with income from other types of scrap in different types of furnaces were made. Despite the small thickness of aluminum foil, which has directly influenced on reducing the yield of the process, the recovery in the induction furnace was efficient.

Key-words: recovery; recycling; aluminum foil; induction furnace; casting.

\section{Agradecimentos}

Agradecemos a Universidade Tecnológica Federal do Paraná (UTFPR) e a Fundação Araucária, pelo apoio na realização da pesquisa.

\section{Referências}

ABAL - Associação Brasileira do Alumínio (a). Reciclagem; 2011. http://www.abal.org.br / reciclagem/latas.asp. Acesso: 29 de junho de 2011.

ABAL - Associação Brasileira do Alumínio (b). Relatório de sustentabilidade a indústria do alumínio; 2007.

ABAL - Associação Brasileira do Alumínio (c). Tabela de classificação de sucatas de alumínio. $2^{\circ}$ ed. São Paulo: Abal, 2006.

ABAL - Associação Brasileira do Alumínio (d). Guia Técnico do Alumínio: geração e tratamento de escoria: vol. 11 São Paulo, SP, 2007. 17p.

ASSOCIACAO BRASILEIRA DE NORMAS TECNICAS. Ligas de alumínio em lingotes para fundição. NBR 13180 - Rio de Janeiro: ABNT, 1994.

BENDER, O. W.; CRUZ, A. C. D. Reciclagem do alumínio pelo uso de forno plasma: forno piloto IPT. Congresso Internacional do Alumínio, 2, São Paulo. Anais... São Paulo, 2005.

DINIZ, A. G. F. (b). Elevação da rentabilidade e produtividade em fundições de alumínio secundário: uma proposta metodológica. 2007. Mestrado em Engenharia de Produção - Universidade Tecnológica Federal do Paraná Campus Ponta Grossa.

FOGAGNOLO, J. B. et al. Recycling of aluminium alloy and aluminium matrix composite chips by pressing and hot extrusion. Journal of Materials Processing Technology, p. 792-795, 2003.

cross ${ }^{\text {ref }}$

KHOEI, A. R. et al. .Numerical modelling of the rotary furnace in aluminium recycling processes. Journal of Materials Processing Technology, p. 567-572, 2003.

cross ${ }^{\text {ref }}$

KURZAWA, U. Estudo da reciclagem de latas de alumínio por fusão em forno elétrico à indução. 2006. Mestrado em Ciência e Engenharia de Materiais - Universidade Estadual de Santa Catarina.

LOUREIRO FILHO, C. L. O alumínio e o real forte. ABAL, março, 2006.

LUZGIN, V. I. et al. Equipment and technology for recycling nonferrous metals. Metallurgist, v. 48, n. 9, p. 536-538, 2004.

cross'

MASHHADI, A. H.; MOLOODI, A.; GOLESTANIPOUR, M.; KARIMI, E. Z. V. Recycling of aluminium alloy turning scrap via cold pressing and melting with salt flux. Journal of Materials Processing Technology, p. 1-5, 2008. 
NOKITA METAL. Latest developments in recycling aluminium dross and scrap using tilting rotary furnaces. Disponível: <http://www.noktametal.com/rtf-nm-en.htm >. Acesso: 15 Jul. 2008.

POPOVICI, M. Geração e destinação dos subprodutos da indústria secundária de alumínio. In: V Seminário Internacional de Reciclagem de Alumínio. São Paulo: ABAL, 1999.

SAMUEL, M. A new technique for recycling aluminium scrap. Journal of Materials Processing Technology, p. 117$124,2003$.

cross ${ }^{\text {ref }}$

SCHMITZ, C. Handbook of aluminium recycling: fundamentals, mechanical preparation, metallurgical processing e plant design. Essen: Valkan-Vergal GmbH, 2006.

SZENTE, R. N.; SCHROETER, R.A; GARCIA, M. G. AND BENDER O.W. Recovering aluminium via plasma processing. JOM Journal of the Minerals, Metals and Materials, v. 47, n. 11, p.52-55, nov. 1997.

TENÓRIO, J. A. S.; ESPINOSA, D. C. R. Effect of salt/oxide interaction on the process of aluminum recycling. Journal of Light Metal 2, p. 89-93, 2002.

cross ${ }^{\text {ref }}$

TENÓRIO, J. A. S.; CARBONI, M. C.; ESPINOSA, D. C. R. Recycling of aluminum:effect of fluoride additions on the salt viscosity and on the alumina dissolution. Journal Light Metal 1 p. 195-198, 2001.

crossef

VERRAN, G. O.; KURZAWA, U. An experimental study of aluminum can recycling using fusion in induction furnace. Resources, Conservation and Recycling, p. 731-736, 2008.

crossef

VERRAN, G. O. et al. Reciclagem de latas de alumínio visando melhor rendimento e qualidade metalúrgica no alumínio obtido. Revista Materiais, v. 10, n. 1, p. 72-79, 2005.

VIEIRA, M. M. F.; PAULA, A. C. Análise institucional do campo da reciclagem de latas de alumínio do Estado do Rio de Janeiro. Cadernos Gestão Social, v.2, n.1, p.27-46, 2009.

XIAO, Y; REUTER, M. A. Recycling of distributed aluminium turning scrap. Minerals Engineering, p. 963-970, 2002.

crossef

ALVARENGA, A.; NOVAES, A. Logística Aplicada - suprimento e distribuição física. São Paulo: Edgard Blücher, 2000 .

Enviado em: 18/01/2011

Aprovado em: 24/06/2011 